\title{
Predictors of illness acceptance in women with endometriosis
}

\begin{abstract}
BACKGROUND
The study aimed to identify significant predictors of illness acceptance in women with endometriosis. As potential predictive factors, variables related to the disease (pain frequency, co-morbid infertility, diagnostic delay, years of living with the diagnosis), demographic variables (age, place of residence, education, income, the fact of having children) and psychological variables (pain coping strategies) were taken into account.
\end{abstract}

\section{PARTICIPANTS AND PROCEDURE}

The study participants - 247 women with endometriosis were recruited in Poland in medical facilities from 6 large voivodship cities and through a patients' association. The participants filled in the following questionnaires: the Acceptance of Illness Scale (AIS), Endometriosis Health Profile-30 (EHP-30), and the Coping Strategies Questionnaire (CSQ). The data were analysed with the method of stepwise hierarchical regression.

\section{RESULTS}

The final significant model explained $24 \%$ of the variance of the AIS score. The model consisted of the following vari- ables: pain frequency, reinterpreting pain sensations, pain catastrophizing and praying/hoping. Only two variables were significant predictors in this model: pain frequency and pain catastrophizing. Years with diagnosis, age, diagnostic delay, place of residence, education, income, and the fact of having children were not significant.

\section{CONCLUSIONS}

The interventions addressed to patients should support their acceptance of chronic pain and help them to develop adaptive pain coping strategies. Due to the co-morbidity of endometriosis-related pain and depression the inclusion of antidepressant pharmacotherapy and psychotherapy based on cognitive techniques is recommended.

\section{KEY WORDS}

pain; infertility; endometriosis; illness acceptance

ORGANizATION - 1: Department of Health and Work Psychology, Nofer Institute of Occupational Medicine, Lodz, Poland . 2: Institute of Psychology, University of Lodz, Lodz, Poland

Authors' Contributions - A: Study design - B: Data collection - C: Statistical analysis - D: Data interpretation .

E: Manuscript preparation · F: Literature search · G: Funds collection

CORRESPONDING AUthor - Aleksandra Andysz, Department of Health and Work Psychology, Nofer Institute

of Occupational Medicine, 8 Saint Teresa Str., 91-348 Lodz, Poland, e-mail: aleksandra.andysz@imp.lodz.pl

to Cite this ARTicle - Andysz, A., \& Merecz-Kot, D. (2021). Predictors of illness acceptance in women with endometriosis.

Health Psychology Report, 9(3), 240-251. https://doi.org/10.5114/hpr.2020.97914

RECEIVED 13.05.2020 • REVIEWED 11.06.2020 • ACCEPTED 18.06.2020 • PUBLISHED 06.08.2020 


\section{BACKGROUND}

Endometriosis is a chronic disease associated with stressful and prolonged treatment, high risk of recurrence and co-occurring infertility. Thus, it causes a heavy burden on both the body and the psyche of patients.

Every chronic condition including endometriosis challenges routines of life and imposes changes which constitute a set of demands the patient needs to face. In the light of stress theories, these demands initiate an adjustment process which leads to adaptation to the new life conditions shaped by both symptoms of disease and its treatment (Sharpe $\&$ Curran, 2006). The acceptance of emerging difficulties related to a chronic condition is one of the aspects of adaptation to illness. Illness acceptance is seen as a profound factor positively affecting the quality of life, wellbeing, physical functioning (Chan, 2012) and medical treatment adherence (Martynow et al., 2017) of chronically ill persons. There are many studies on illness acceptance, its predictors and outcomes in various kinds of medical conditions but not, according to our best knowledge, in endometriosis.

We assume that endometriosis acceptance relates to characteristics of disease (chronicity, pain, infertility, diagnostic delay) and individual characteristics (sociodemographics and strategies of coping with pain). It is the aim of this paper to verify this assumption.

\section{SELECTED CHARACTERISTICS OF ENDOMETRIOSIS}

\section{CHRONICITY}

Diagnosis of chronic illness changes lives, and is often associated with a serious crisis, which takes many years to overcome. It initiates a long-term process of adaptation to the unwanted changes caused by the disease.

There are many definitions of chronic illness, mainly referring to seven main characteristics that are also typical of endometriosis:

1. Long duration: women suffering from endometriosis experience symptoms for many years. Data show that in $97 \%$ of women these symptoms disappear only after menopause (Oxholm et al., 2007).

2. Disease caused by irreversible pathological changes: although the cause of endometriosis is unknown, researchers agree that it results from abnormalities in crucial physiological processes endocrinal (Bulun et al., 2010) and immunological (Berbic \& Fraser, 2011).

3. Slow and gradual course of illness: endometriosis develops relatively slowly; periods of remission are intertwined with phases of recurrence and exacerbation of symptoms.

4. The essence: endometriosis is a systemic disease that debilitates the functioning of many organs and even entire systems.

5. Somatic as well as psychosocial consequences: at the cellular level, endometriosis leads to damage in the organs, some of them being irreversible. It negatively affects performing social roles - limits participation in social life, makes it impossible or difficult to perform many everyday activities and to continue education and professional development, and also significantly reduces the ability to work (Andysz et al., 2018).

6. Symptoms: the course and development of endometriosis can be controlled, but full recovery is not possible. It requires physiotherapy and changes in lifestyle that will maintain the effects of therapy and protect against recurrence. Some patients dealing with suffering which is not curable by conventional medicine reach for alternative methods. Psychotherapy and psychiatric treatment also may help in the case of mental health disorders due to chronic stress associated with the disease.

7. Long-term treatment not leading to recovery: $\mathrm{Pa}$ tients need to be under constant or periodic care of a gynaecologist (to modify/maintain pharmacotherapy, periodically undergo ultrasound) because of the long-term treatment and the risks of symptoms reoccurrence. Since various other health problems accompany endometriosis (gastrointestinal problems, urological problems) patients are also under the care of doctors of other specialities.

\section{PAIN}

The painfulness of endometriosis makes this disease particularly difficult to accept. Endometriosis-related pain includes a combination of different experiences - acute and chronic pain; menstrual and pelvic pain; local and diffuse pain. The pain affects various areas of the body (abdomen, intestines, rectum) and occurs during various activities: walking, defecation, sexual intercourse (Denny, 2004; Ferrero et al., 2005; Fourquet et al., 2010; Stratton \& Berkley, 2010). According to some (Fourquet et al., 2010), the adverse impact of endometriosis on the quality of life and mental health of patients is more severe than in other gynaecological diseases. Studies show that because of the pain, the deterioration of the quality of life in endometriosis can be compared to the one in cancer (Nnoaham et al., 2011). The pain associated with endometriosis is perceived as uncontrollable and unpredictable; thus, many patients believe it determines the rhythm of their lives.

The problem of pain results not only in physical suffering, but also a psychological burden. Previous studies show that women with endometriosis suffer
Predictors of illness acceptance in women with endometriosis 
from hyperalgesia (increased sensitivity to pain) and allodynia (experiencing pain as the response to stimuli which do not cause pain in healthy people) (Lundeberg \& Lund, 2008). As pain is a common experience in endometriosis an important part of the treatment is pain management, which includes pharmacotherapy, physical therapy, education and psychotherapy.

\section{INFERTILITY}

Aleksandra

Andysz, Dorota Merecz-Kot

Prolonged and fruitless efforts to have a child are traumatic for people who want to be parents (Herrmann et al., 2011). Endometriosis is considered one of the leading causes of infertility. It is diagnosed in about $25-40 \%$ of women who have problems with conceiving a child (Ozkan et al., 2008).Studies indicate that endometriosis can negatively affect any of the physiological stages leading up to pregnancy (Mon Khine et al., 2016). The chances of women who are ill to conceive are also reduced because of endometrial cysts and structural changes in ovarian tissue that contribute to the reduction of the ovarian reserve (Kitajima et al., 2011). This reserve is additionally reduced by surgical removal of endometrial cysts (Somigliana et al., 2003). Moreover, many women suffering from endometriosis also experience sexual intercourse as painful (Ferrero et al., 2005), which decreases the frequency of intercourse or even prevents women from having sexual relations.

\section{ILLNESS ACCEPTANCE AS A SIGN \\ OF ADAPTATION TO LIVING \\ WITH A CHRONIC ILLNESS}

Acceptance of chronic disease can be defined as an attitude of a chronically ill person characterised by the assumption that illness with its consequences is an integral and inevitable part of life to which one needs to get accustomed. For many people adopting such an attitude seem to be challenging or even impossible. Acceptance of the fact that the life changes caused by a chronic disease can be irreversible and followed by loss requires time, support, and a massive mental effort. Illness acceptance can also be understood as a kind of "negotiated contract" between the patient and the disease. The patient "agrees" to the presence of disease, and decides to deal with the limitations and changes that it caused (Zalewska et al., 2007).

Illness acceptance is considered as an important factor maintaining general well-being. Studies regarding different groups of patients have shown a positive association between disease acceptance and the quality of life (Baneh et al., 2018; Bień et al., 2015; Jankowska-Polańska et al., 2018; Mroczek et al., 2017; Obiego et al., 2017). Illness acceptance also negatively correlates with depressive symptoms
(Uchmanowicz et al., 2016). It also influences the current as well as distant situation of the patient - it is associated with an improvement in adherence to prescribed drugs (Jankowska-Polańska et al., 2016a; Qiu et al., 2019) and more frequent self-care and pro-health behaviours (Bień et al., 2015; JankowskaPolańska et al., 2016a; Qiu et al., 2019; Rode \& Rode, 2018; Uchmanowicz et al., 2016). Therefore, the level of disease acceptance can be considered as a measure of the effectiveness of medical therapy (Mroczek et al., 2015). One study found that patients with chronic obstructive pulmonary disease (COPD) who did not accept their illness showed more difficulties in their daily activities and in understanding their disease (Grassion et al., 2019). Other empirically confirmed effects of accepting the illness include higher self-esteem and self-efficacy among patients (Rode \& Rode, 2018), greater independence in the disease (Rosińczuk \& Kołtuniuk, 2017), better mental well-being (Jankowska-Polańska et al., 2016a; Jankowska-Polańska et al., 2016b; Rosińczuk \& Kołtuniuk, 2017; Uchmanowicz et al., 2016), greater vitality despite pain and less frequent use of analgesics (Kratz et al., 2018).

\section{STUDY AIM}

The aim of the study was to identify significant predictors of illness acceptance in patients with endometriosis. Despite the nuisance of this illness and its effects on mental health, according to the authors' best knowledge, this topic has not been investigated yet. Knowledge on the conditions for the acceptance of endometriosis will enable planning interventions aimed at minimizing its negative mental consequences.

\section{PARTICIPANTS AND PROCEDURE}

\section{PARTICIPANTS}

The study protocol was accepted by the Bioethics Committee of the Nofer Institute of Occupational Medicine. Patient recruitment and data collection lasted from 2014 to 2016 . The study participants were recruited in Poland, in medical facilities from 6 voivodship cities and through a patients' association.

To be included in the study, a patient had to be diagnosed with endometriosis, regardless of the method of diagnosis. The method of selecting patients for the sample was the convenient one - participants were selected based on availability and willingness to take part. The medical records were not verified.

Depending on the place of recruitment, the qualification for inclusion was performed by a gynaecologist or participants volunteered themselves. No exclusion criterion was applied. 
The participants received a set of questionnaires, each set packed in a separate envelope. All of them were informed about the purpose of the study (the set included an attachment with the information for patients) and they completed the questionnaires anonymously. A woman receiving a set of questionnaires could give it back without completing it. The participants filled in the questionnaires in the premises of the medical facilities where they were recruited (hospitals or clinics) or at home.

The output database consisted of 360 records. Due to missing data in any measured variable 74 records were removed (21\% of the sample). Analyses were performed based on 247 records.

\section{MEASUREMENT}

Acceptance of Illness Scale by Felton et al. (1984) adapted to Polish by Juczyński (2009) - a one-dimensional tool to study adults who are currently ill. It contains eight statements describing the negative consequences of the disease, to which the respondent refers by choosing a response on a 5 -degree scale ranging from 1 (I strongly agree) to 5 (I strongly disagree). Example of a scale statement: "I have difficulty adapting to the limitations imposed by the disease".

The higher the score is, the greater is the acceptance of the disease and the better the adaptation to living with the disease. The overall disease acceptance rate is the sum of all points, which can range from 8 to 40 points. The reliability of the scale measured with Cronbach's $\alpha$ coefficient equalled 90.

Pain scale from the Endometriosis Health Profile-30 (EHP-30; Jones et al., 2001) aimed at measuring the quality of life of patients with endometriosis. The Polish version of the tool is made available for scientific purposes by the University of Oxford.

The questionnaire allows one to estimate the general quality of life with endometriosis as well as the quality of life in five dimensions: pain, control and powerlessness, emotional well-being, social support and self-image. In this analysis, only the results of the pain scale were considered. The scale includes questions on how the disease-induced pain makes it impossible to perform housework, work, rest (example item: "Been unable to go to social events because of the pain?"; the reliability of the scale as measured with Cronbach's $\alpha$ was .97).

The general score and scores on particular scales ranged from 0 to 100 . The higher the result, the more often the symptoms were experienced. The response scale ranges from 0 (never) to 4 (always). Respondents are asked to refer to their experiences of the past 4 weeks.

The Coping Strategies Questionnaire (CSQ; Juczyński, 2009) used to assess the frequency of seven pain management strategies: diverting attention (for ex- ample, "I try to think of something pleasant"; Cronbach's $\alpha=.80$ ); reinterpreting pain sensations ("I try to feel distant from the pain, almost as if the pain was in somebody else's body"; $\alpha=.87$; catastrophizing ("It is terrible and I feel it is never going to get any better"; $\alpha=.89$ ); ignoring pain sensations ("I don't pay any attention to it"; $\alpha=.82$ ); praying/hoping ("I know someday someone will be there to help me and it will go away for a while"; $\alpha=.79$ ); coping self-statements ("I tell myself I can't let the pain stand in the way of what I have to do"; $\alpha=.84$ ) and increased behavioural activity ("I leave the house and do something, such as going to the movies or shopping"; $\alpha=.83$ ).

The score on each scale ranges from 0 to 36 . The higher the score, the more often the strategy is used.

\section{STATISTICAL ANALYSIS}

The following variables were considered as potential predictors of illness acceptance:

- variables related to the disease (painfulness of endometriosis, comorbid infertility, diagnostic delay, years of living with the diagnosis),

- demographic variables (age, place of residence, education, income, fact of having children),

- psychological variables: pain coping strategies.

To analyse the data and address the research aim, stepwise hierarchical regression was used.

In the first step, the variables considered to be the strongest predictors of endometriosis acceptance were introduced: the frequency of pain and infertility. In the second step: the subscales of the CSQ questionnaire that correlated with the AIS questionnaire: the reinterpretation of pain sensations, catastrophic pain and praying/hoping (see Table 4). In the third step, we controlled for: demographic variables (age, place of residence, education, income, having children) and two disease-related variables (diagnostic delay and years of living with the diagnosis).

The analyses were carried out using the statistical program SPSS version 23.

\section{RESULTS}

The study group included young women, most of them being residents of large cities, having higher education, assessing their economic situation as good or very good and having no children. Demographic variables and variables related to endometriosis characteristics and disease history are presented in Tables 1-3.

Three significant correlations between the AIS and CSQ scales were found. All correlations were negative. Moderate correlations were found between the illness acceptance scale and the reinterpreting pain sensations scale and the praying/hoping scale. Mod-
Predictors of illness acceptance in women with endometriosis 
erate correlations were found between the illness acceptance scale and the pain catastrophizing (Table 4).

Pain and infertility introduced into the model in the first step explained $18 \%$ of the variance of illness acceptance. Infertility turned out to be insignificant. The addition of pain management strategies in the

\section{Table 1}

Aleksandra Andysz, Dorota Merecz-Kot

Demographic characteristics of the sample

\begin{tabular}{cc}
\hline & $M(S D), \quad n(\%)$ \\
$\min -\max$ & \\
\hline Age & $32.52(6.21)$, \\
& $20-60$
\end{tabular}

Place of residence

City of more than 100,000

inhabitants

City 20,000-100,000

inhabitants

City of less than

20,000 inhabitants

Country

Education

Vocational secondary

education

General secondary

education

Master's degree/

Bachelor's degree

Income

Not enough for basic

needs

Sufficient only for basic

needs

Enough to meet your

current needs without worrying whether you will have enough money until the end of the month

Enough to make small savings for unplanned expenses

Big enough to live without much sacrifice and save for the future.

\section{Children}

No

Yes
$141(57)$

$49(20)$

$27(11)$

$30(12)$

second step maintained the significance of the model and increased the percentage of the explained variance to $24 \%$. The final significant model $(p<.001)$ consisted of the following variables: pain, reinterpreting pain sensations, pain catastrophizing and praying/hoping (Table 5). Only two variables were significant predictors in this model: pain and pain catastrophizing. The results for the reinterpreting of pain sensations was on the threshold of significance.

Thus, the lower the score on the EHP-30 pain scale and the lower the score on the pain catastrophizing scale, the higher the score on the AIS.

\section{Table 2}

Characteristics of the group in terms of psychometric data

\begin{tabular}{ll} 
& $M(S D)$, min-max \\
\hline Illness acceptance (AIS) & $28.34(8.64), 8-40$ \\
Health-related quality of life & \\
(EHP-30) &
\end{tabular}

\section{Pain}

$39.26(27.73), 0-100$

Coping with pain strategies (CSQ)

Diverting attention

13.61 (8.36), 0-33

Reinterpreting pain 9.12 (8.56), 0-36 sensations

Pain catastrophizing

14.49 (9.49), 0-36

Ignoring pain sensations

12.57 (8.31), 0-36

Praying/hoping

16.22 (9.15), 0-36

Coping self statements

19.05 (8.75), 0-36

Increased behavioural activity

14.79 (8.53), 0-36

Table 3

Characteristics of the group in terms of disease-related data

\begin{tabular}{lcc}
\hline & $\begin{array}{c}M(S D), \\
\text { min-max }\end{array}$ & $n(\%)$ \\
\hline Diagnostic delay & $5.92(6.30)$, & \\
& $0-28$ & \\
Years of living with & $3.34(3.83)$, & \\
diagnosis & $0-19$ & \\
Infertility & & \\
$\quad$ Yes & & $86(35)$ \\
$\quad$ No & & $161(65)$ \\
\hline
\end{tabular}


Correlations between illness acceptance (AIS score) and coping with pain strategies (subscales of the CSQ questionnaire)

\begin{tabular}{lccccccc}
\hline $\begin{array}{c}\text { Diverting } \\
\text { attention }\end{array}$ & $\begin{array}{c}\text { Reinterpreting } \\
\text { pain } \\
\text { sensations }\end{array}$ & $\begin{array}{c}\text { Pain } \\
\text { catastrophizing }\end{array}$ & $\begin{array}{c}\text { Ignoring } \\
\text { pain } \\
\text { sensations }\end{array}$ & $\begin{array}{c}\text { Praying/ } \\
\text { hoping }\end{array}$ & $\begin{array}{c}\text { Coping self } \\
\text { statements }\end{array}$ & $\begin{array}{c}\text { Increased } \\
\text { behavioural } \\
\text { activity }\end{array}$ \\
\hline AIS & -.10 & $-.13^{*}$ & $-.42^{* *}$ & .03 & $-.23^{* *}$ & -.02 & .00 \\
\hline Note. ${ }^{*} p<.01,{ }^{* *} p<.05$. & & & & &
\end{tabular}

\section{DISCUSSION}

The results of this study confirm the importance of chronic pain-related variables: the frequency of the experienced pain and pain catastrophizing as factors shaping the acceptance of endometriosis. Demographic and disease-related variables, such as infertility, diagnostic delay or years of living with the diagnosis, turned out to be insignificant.

Compared to other studies, patients with endometriosis on reported comparable illness acceptance to patients with gestational diabetes (Baneh et al., 2018), polycystic ovarian syndrome (Rzońca et al., 2018), breast cancer (Czerw et al., 2016b) and circulatory, urinary, and respiratory diseases (Janowski et al., 2013). The burden of endometriosis, therefore, corresponds to that of other illnesses, the severity of which is not disputed, i.e. chronic respiratory diseases or cardiovascular diseases.

The significance of predictors related to pain shows that in the study group illness acceptance depended on the acceptance of pain and coping strategy - in this case, the frequency of using pain catastrophizing. The less often patients experienced the endometriosis-related pain and the less often they used the catastrophizing pain coping strategy, the greater was their acceptance of the disease. This is in line with the conclusions of the review of endometriosis studies indicating pain as the biggest stressor in this disease (Zarbo et al., 2018). Concomitant pain generates specific physical and psychological costs. Mental suffering caused by pain changes the way patients experience themselves and the world. The pain in endometriosis is severe, paroxysmal and unpredictable. Experiencing pain of that type significantly reduces the quality of life, hinders satisfaction with functioning in every sphere of life and makes it impossible to perform the desired family, professional and social activities. It also worsens work ability, causes long-term sick leave, and in extreme cases even leads to losing one's job (Andysz et al., 2018). Being such an impeding factor, it also hinders the acceptance and adaptation to chronic illness. In endometriosis, the pain sets the rhythm of life, and dictates its cruel conditions.
Literally, it shapes the patients' lives (Huntington \& Gilmour, 2005), frequently limiting the scope of activity and functioning of the affected patients.

Importantly, our findings also indicate that pain catastrophizing is a meaningful predictor of low acceptance of the disease. Catastrophizing of pain might be defined as "an exaggerated negative mental set brought to bear during actual or anticipated pain experience" (Sullivan et al., 2001, p. 53). The evidenced association between pain catastrophizing and illness acceptance corresponds with the studies on the impact of such coping with pain on adaptation to living with a chronic condition. The studies clearly indicate its negative, non-adaptive influence on various aspects of adaptation to the disease. Pain catastrophizing contributes to the intensification or persistence of pain sensations (Carey et al., 2014; Sullivan et al., 2001), and it is strongly associated with helplessness, increased stress, anxiety and depression (Esteve et al., 2007; Keffe et al., 2004; Richardson et al., 2009; Walsh et al., 2003), as well as disability (Lami et al., 2018; Vowles et al., 2008). Pain catastrophizing also results in specific behaviours related to treatment, i.e. more frequent doctor's appointments (Quartana et al., 2009), longer stays in hospital (Wright et al., 2017), and the use of strong analgesics (Valdes et al., 2015). The catastrophic attitude of patients may prompt doctors to take a more intensive and invasive approach to treatment (Sullivan et al., 2001). The patients' complaints about the experience of severe pain make doctors look for its source in organs and thus refer such patients for surgery, sometimes multiple, more frequently (Walsh et al., 2003).

Separate attention should also be paid to insignificant results. One of the insignificant predictors of endometriosis acceptance was infertility. Endometriosis is considered one of the leading causes of infertility. It is estimated that in women with problems with conceiving a child, endometriosis co-occurs in about $20-50 \%$ of cases (Gao et al., 2006; Ozkan et al., 2008; Selçuk \& Bozdağ, 2013). On the basis of data from Poland from 2005-2010 covering 1705 cycles of infertility treatment with IVF ICSI, the percentage of endometriosis in infertility was estimated at 10-15\% of cases (Milewski et al., 2013). In infertility, there is
Predictors of illness acceptance in women with endometriosis 


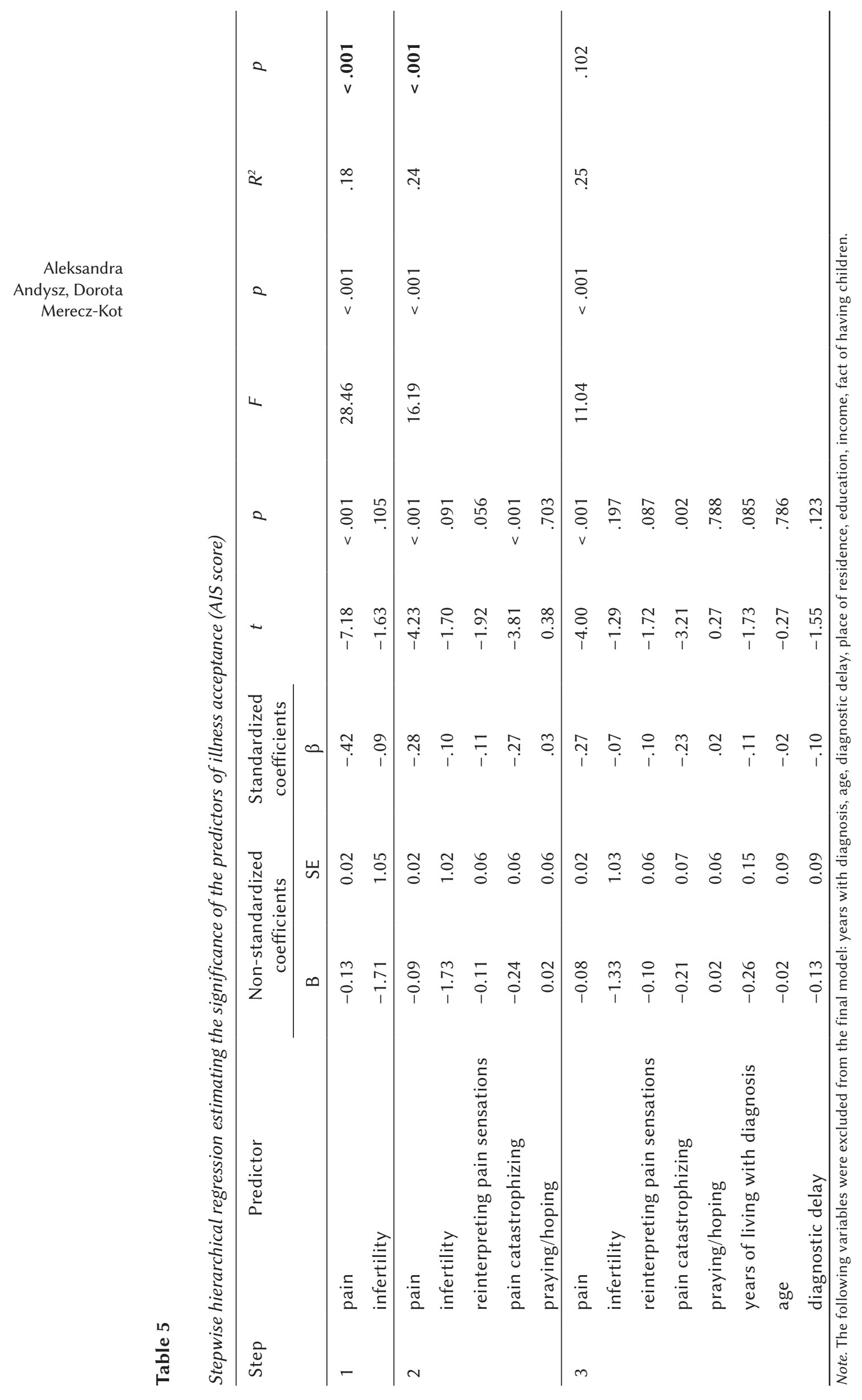


a problem of growing and intensifying single crises associated with treatment and each monthly cycle that does not bring pregnancy (Dembińska, 2013). Until the moment of having the desired pregnancy and giving birth to a healthy child, or until a decision is made, for example, to adopt or accept childlessness, the experience of infertility turns into a chronic crisis leading to a life of continuous mental suffering (McCarthy, 2008). Therefore we find this result rather surprising. Also disease duration, which in the study of patients with COPD (Jankowska-Polańska et al., 2016b), hypertension (Baczewska et al., 2015) and multiple sclerosis (Król et al., 2015) was a significant predictor of illness acceptance (shorter time since the diagnosis correlated with better acceptance), here turned out to be insignificant. Demographic variables (age, place of residence, education, income, having children) were also insignificant. In other studies higher socio-economic status was related to better access to health care, better treatment, better coping with everyday life and in general greater illness acceptance in pregnant women with diabetes, women with PCOS and patients with cancer (Bien et al., 2015; Czerw et al., 2016a; Czerw et al., 2017; Rzońca et al., 2018). Some studies showed mixed results referring to age - younger age predicted better illness acceptance (Baczewska et al., 2015; Cipora et al., 2018; Jankowska-Polańska et al., 2016b; Janowski et al., 2014; Mroczek et al., 2015; Rogon et al., 2017), whereas another one showed no relationship (Czerw et al., 2016a); place of residence - some studies indicated that patients living in large cities had higher acceptance (Baczewska et al., 2015; Czerw et al., 2016a), yet, in another study on breast cancer patients the relationship between these variables was insignificant (Cipora et al., 2018). Also there was no significant relation between illness acceptance and level of education in our study. Other research on this issue brought ambiguous results - a few studies showed that better education is associated with higher illness acceptance just as in research on patients with COPD (Jankowska-Polańska et al., 2016b; Mroczek et al., 2015), hypertension (Baczewska et al., 2015) and breast cancer (Czerw et al., 2016b), while in other studies (on breast cancer patients and patients with pancreatic and colorectal cancer), this relation was insignificant (Cipora et al., 2018; Czerw et al., 2016b).

In conclusion, the chronicity, incurability, and the resultant difficulties debilitating patients' activity in all spheres of life make endometriosis difficult to accept. This research evidenced that it is the experience of and the attitude towards pain that constitute the greatest burden. The quality of patients' lives depends on their attitude towards the pain and the ways of coping with it. The acceptance of the inevitable pain and using adaptive coping strategies may contribute to a greater acceptance of the difficult experience of this disease.

\section{CONCLUSIONS}

As pain has the most significant effect on illness acceptance in endometriosis, any intervention aimed at enhancing or maintaining illness acceptance should address the issue of pain and its management. Due to significant comorbidity of endometriosis-related pain and depression (Lorençatto et al., 2006) the inclusion of antidepressant pharmacotherapy and psychotherapy is recommended to improve well-being and increase illness acceptance (Uchmanowicz et al., 2016).

Pain management could also be improved by psychotherapy based on cognitive techniques such as cognitive behavioural therapy (Lami et al., 2018; Turner et al., 2016), acceptance and commitment therapy (ACT) (De Boer et al., 2014; Trompetter et al., 2015), the mindfulness-based stress reduction approach (Turner et al., 2016) or mindfulness-based cognitive therapy (Day \& Thorn, 2016). Changing illness representations and reducing catastrophizing, strengthening the acceptance and behavioural activation are the main targets of psychotherapy (Gillanders et al., 2013).

\section{LIMITATIONS}

This study has its limitations. First, the cross-sectional nature does not allow cause and effect to be determined: is the illness acceptance determined by pain frequency, or does the pain determine the illness acceptance? It is also impossible to verify whether pain catastrophizing is the effect of the pain or, vice versa, whether frequent pain causes its catastrophizing. These questions should be examined in future studies.

\section{FUTURE DIRECTIONS}

Future studies shall focus on deeper exploration of the determinants of endometriosis acceptance. This illness still frequently remains undiagnosed and since it refers to menstruation and fertility, it is associated with a social taboo. Patients are often left alone in their suffering. They cannot count on understanding and compassion because they often find it difficult to prove how much they suffer - their pain is invisible. Little awareness of what endometriosis means causes that their suffering is ignored. In many cases, patients are accused of exaggerating their suffering. Future research could, therefore, investigate the social determinants of acceptance vs. the lack of acceptance of this illness.

\section{ACKNOWLEDGMENTS}

The authors would like to express their gratitude to the anonymous survey participants who wanted to
Predictors of illness acceptance in women with endometriosis 
share their experience and to those who helped in collecting the data. Many thanks to: Prof. Marian Szamatowicz, Prof. Ewa Barcz, Dr Joanna Bubak-Dawidziuk, Dr Zofia Gordon, Dr Paulina Malarkiewicz, Magdalena Matysiak, Dr Justyna Murzyn, Dr Paweł Siekierski, Prof. Robert Spaczyński, Izabela Sulima, Prof. Jacek Szamatowicz, Prof. Krzysztof Szyłło, Prof. Jolanta Walusiak-Skorupa, Dr Tomasz Waśniewski, Katarzyna Zielińska and Prof. Mariusz Zimmer for their assistance on the project.

Aleksandra

Andysz, Dorota Merecz-Kot

The study has been financed from the funds for statutory activities of the Nofer Institute of Occupational Medicine (IMP 21.9).

\section{ENDNOTE}

1 All items are introduced by "During the last 4 weeks how often have you experienced the following because of endometriosis...".

\section{REFERENCES}

Andysz, A., Jacukowicz, A., Merecz-Kot, D., \& Najder, A. (2018). Endometriosis - the challenge for occupational life of diagnosed women: a review of quantitative studies. Medycyna Pracy, 69, 663-671. https://doi.org/10.13075/mp.5893.00737

Baczewska, B., Kropornicka, B., Sepioło, J., Krzyżanowska, E., Olszak, C., Szymczuk, E., \& Daniluk, J. (2015). Acceptance of illness and satisfaction with life among patients with arterial hypertension. Health Problems of Civilization, 3, 31-38. https:// doi.org/10.5114/hpc.2015.57131

Baneh, T. A. B., Khomami, H. M., Mirhadian, L., \& Atrkarroushan, Z. (2018). The relationship between acceptance of illness and quality of life in mothers with gestational diabetes mellitus. Journal of Pharmaceutical Research International, 25, 1-10. https://doi.org/10.9734/jpri/2018/v25i530110

Berbic, M., \& Fraser, I. S. (2011). Regulatory T cells and other leukocytes in the pathogenesis of endometriosis. Journal of Reproductive Immunology, 88, 149-155. https://doi.org/10.1016/J.JRI.2010.11.004

Bień, A., Rzońca, E., Kańczugowska, A., \& IwanowiczPalus, G. (2015). Factors affecting the quality of life and the illness acceptance of pregnant women with diabetes. International Journal of Environmental Research and Public Health, 13, 68. https://doi. org/10.3390/ijerph13010068

Bulun, S. E., Cheng, Y. H., Pavone, M. E., Yin, P., Imir, G., Utsunomiya, H., Thung, S., Xue, Q., Marsh, E. E., Tokunaga, H., Ishikawa, H., Kurita, T.,
\& Su, E. J. (2010). 17-Hydroxysteroid dehydrogenase-2 deficiency and progesterone resistance in endometriosis. Seminars in Reproductive Medicine, 28, 44-50. https://doi.org/10.1055/s-0029-1242992

Carey, E. T., Martin, C. E., Siedhoff, M. T., Bair, E. D., \& As-Sanie, S. (2014). Biopsychosocial correlates of persistent postsurgical pain in women with endometriosis. International Journal of Gynecology and Obstetrics, 124, 169-173. https://doi. org/10.1016/j.ijgo.2013.07.033

Chan, R. (2012). The effect of acceptance on health outcomes in patients with chronic kidney disease. Nephrology, Dialysis, Transplantation, 28, 11-14. https://doi.org/10.1093/ndt/gfs334

Cipora, E., Konieczny, M., \& Sobieszczański, J. (2018). Acceptance of illness by women with breast cancer. Annals of Agricultural and Environmental Medicine, 25, 167-171. https://doi.org/10.26444/aaem/75876

Czerw, A. I., Bilińska, M., \& Deptała, A. (2016a). The assessment of the impact of socio-economic factors in accepting cancer using the Acceptance of Illness Scale (AIS). Contemporary Oncology, 20, 261-265. https://doi.org/10.5114/wo.2015.54901

Czerw, A., Religioni, U., \& Deptała, A. (2016b). Assessment of pain, acceptance of illness, adjustment to life with cancer and coping strategies in breast cancer patients. Breast Cancer, 23, 654-661. https://doi.org/10.1007/s12282-015-0620-0

Czerw, A. I., Religioni, U., Deptała, A., \& Fronczak, A. (2017). Pain, acceptance of illness, adjustment to life with cancer and coping strategies in prostate cancer patients. Archives of Medical Science, 13, 14591466. https://doi.org/10.5114/aoms.2016.58458

Day, M. A., \& Thorn, B. E. (2016). The mediating role of pain acceptance during mindfulness-based cognitive therapy for headache. Complementary Therapies in Medicine, 25, 51-54. https://doi.org/10.1016/ j.ctim.2016.01.002

De Boer, M. J., Steinhagen, H. E., Versteegen, G. J., Struys, M. M. R. F., \& Sanderman, R. (2014). Mindfulness, acceptance and catastrophizing in chronic pain. PLoS One, 9, e87445. https://doi.org/10.1371/ journal.pone.0087445

Dembińska, A. (2013). Rola nadziei w pomocy psychologicznej kobietom leczącym niepłodność [The role of hope in psychological help for women treating infertility]. Sztuka Leczenia, 1/2, 9-20.

Denny, E. (2004). Women's experience of endometriosis. Journal of Advanced Nursing, 46, 641-648. https://doi.org/10.1111/j.1365-2648.2004.03055.x

Esteve, R., Ramírez-Maestre, C., \& López-Martínez, A. E. (2007). Adjustment to chronic pain: The role of pain acceptance, coping strategies, and painrelated cognitions. Annals of Behavioral Medicine, 33, 179-188. https://doi.org/10.1007/BF02879899

Felton, B. J., Revenson, T. A., \& Hinrichsen, G. A. (1984). Stress and coping in the explanation of psychological adjustment among chronically ill adults. 
Social Science \& Medicine, 18, 889-898. https://doi. org/10.1016/0277-9536(84)90158-8

Ferrero, S., Esposito, F., Abbamonte, L. H., Anserini, P., Remorgida, V., \& Ragni, N. (2005). Quality of sex life in women with endometriosis and deep dyspareunia. Fertility and Sterility, 83, 573-579. https:// doi.org/10.1016/j.fertnstert.2004.07.973

Fourquet, J., Gao, X., Zavala, D., Orengo, J. C., Abac, S., Ruiz, A., Laboy, J., \& Flores, I. (2010). Patients' report on how endometriosis affects health, work, and daily life. Fertility and Sterility, 93, 2424-2428. https://doi.org/10.1016/j.fertnstert.2009.09.017

Gao, X., Yeh, Y. C., Outley, J., Simon, J., Botteman, M., \& Spalding, J. (2006). Health-related quality of life burden of women with endometriosis: a literature review. Current Medical Research and Opinion, 22, 1787-1797. https://doi.org/10.1185/03007 $9906 \times 121084$

Gillanders, D. T., Ferreira, N. B., Bose, S., \& Esrich, T. (2013). The relationship between acceptance, catastrophizing and illness representations in chronic pain. European Journal of Pain, 17, 893-902. https:// doi.org/10.1002/j.1532-2149.2012.00248.x

Grassion, L., Le Guillou, F., Izadifar, A., Piperno, D., \& Raherison-Semjen, C. (2019). Factors associated with poor acceptance of illness in patients with COPD. Revue Des Maladies Respiratoires, 36, 461-467. https://doi.org/10.1016/j.rmr.2018.11.010

Herrmann, D., Scherg, H., Verres, R., Von Hagens, C., Strowitzki, T., \& Wischmann, T. (2011). Resilience in infertile couples acts as a protective factor against infertility-specific distress and impaired quality of life. Journal of Assisted Reproduction and Genetics, 28, 1111-1117. https://doi.org/10.1007/s10815-0119637-2

Huntington, A., \& Gilmour, J. A. (2005). A life shaped by pain: Women and endometriosis. Journal of Clinical Nursing, 14, 1124-1132. https://doi.org/10.1111/ j.1365-2702.2005.01231.x

Jankowska-Polańska, B., Blicharska, K., Uchmanowicz, I., \& Morisky, D. E. (2016a). The influence of illness acceptance on the adherence to pharmacological and non-pharmacological therapy in patients with hypertension. European Journal of Cardiovascular Nursing, 15, 559-568. https://doi. org/10.1177/1474515115626878

Jankowska-Polańska, B., Kaczan, A., Lomper, K., Nowakowski, D., \& Dudek, K. (2018). Symptoms, acceptance of illness and health-related quality of life in patients with atrial fibrillation. European Journal of Cardiovascular Nursing, 17, 262-272. https://doi. org/10.1177/1474515117733731

Jankowska-Polańska, B., Kasprzyk, M., Chudiak, A., \& Uchmanowicz, I. (2016b). Relation between illness acceptance and quality of life in patients with chronic obstructive pulmonary disease (COPD). Advances in Respiratory Medicine, 85, 3-10. https:// doi.org/10.5603/PiAP.a2015.0079
Janowski, K., Kurpas, D., Kusz, J., Mroczek, B., \& Jedynak, T. (2013). Health-related behavior, profile of health locus of control and acceptance of illness in patients suffering from chronic somatic diseases. PLoS One, 8, e63920. https://doi.org/10.1371/ journal.pone.0063920

Janowski, K., Kurpas, D., Kusz, J., Mroczek, B., \& Jedynak, T. (2014). Emotional control, styles of coping with stress and acceptance of illness among patients suffering from chronic somatic diseases. Stress and Health, 30, 34-42. https://doi.org/10.1002/smi.2493

Jones, G., Jenkinson, C., \& Kennedy, S. (2001). The endometriosis health profile user manual. Oxford University Innovation.

Juczyński, Z. (2009). Narzędzia pomiaru w promocji i psychologii zdrowia [Methods in health promotion and health psychology]. Pracownia Testów Psychologicznych PTP.

Keffe, F. J., Rumble, M. E., Scipio, C. D., Giordano, L. A., \& Perri, L. M. (2004). Psychological aspects of persistent pain: current state of the science. The Journal of Pain, 5, 195-211. https://doi. org/10.1016/j.jpain.2004.02.576

Kitajima, M., Defrère, S., Dolmans, M., \& Colette, S. (2011). Endometriomas as a possible cause of reduced ovarian reserve in women with endometriosis. Fertility and Sterility, 96, 685-691. https://doi. org/10.1016/j.fertnstert.2011.06.064

Kratz, A. L., Murphy, J. F., Kalpakjian, C. Z., \& Chen, P. (2018). Medicate or meditate? Greater pain acceptance is related to lower pain medication use in persons with chronic pain and spinal cord injury. The Clinical Journal of Pain, 34, 357-365. https:// doi.org/10.1097/AJP.0000000000000550

Król, J., Szcześniak, M., Koziarska, D., \& Rzepa, T. (2015). Time perception and illness acceptance among remitting-relapsing multiple sclerosis patients under treatment. Psychiatria Polska, 49, 911-920. https://doi.org/10.12740/PP/38740

Lami, M. J., Martínez, M. P., Miró, E., Sánchez, A. I., \& Guzmán, M. A. (2018). Catastrophizing, acceptance, and coping as mediators between pain and emotional distress and disability in fibromyalgia. Journal of Clinical Psychology in Medical Settings, 25, 80-92. https://doi.org/10.1007/s10880-018-9543-1

Lorençatto, C., Petta, C. A., Navarro, M. J., Bahamondes, L., \& Matos, A. (2006). Depression in women with endometriosis with and without chronic pelvic pain. Acta Obstetricia et Gynecologica Scandinavica, 85, 88-92. https://doi. org/10.1080/00016340500456118

Lundeberg, T., \& Lund, I. (2008). Is there a role for acupuncture in endometriosis pain, or 'endometrialgia'? Acupuncture in Medicine, 26, 94-110. https:// doi.org/10.1136/aim.26.2.94

Martynow, A., Lefek, K., Wierzbicka, B., Chudiak, A., Lomper, K., \& Jankowska-Polańska, B. (2017). Effect of acceptance of illness on treatment adherence
Predictors of illness acceptance in women with endometriosis 
in atrial fibrillation patients. Journal of Education, Health and Sport, 7, 154-170. https://doi.org/10.5281/ zenodo.573092

McCarthy, M. P. (2008). Women's lived experience of infertility after unsuccessful medical intervention. Journal of Midwifery and Women's Health, 53, 319324. https://doi.org/10.1016/j.jmwh.2007.11.004

Milewski, R., Milewska, A., \& Czarnecki, J. (2013). Analiza profilu demograficznego pacjentów leczonych z powodu niepłodności metodami rozrodu wspomaganego w latach 2005-2010 [Analysis of the demographic profile of patients treated for infertility using assisted reproductive techniques in 2005-2010]. Ginekologia Polska, 84, 610-614. https://doi.org/10.17772/gp/1612

Mon Khine, Y., Taniguchi, F., \& Harada, T. (2016). Clinical management of endometriosis-associated infertility. Reproductive Medicine and Biology, 15, 217-225. https://doi.org/10.1007/s12522-016-0237-9

Mroczek, B., Parzuchowska, K., Jasińska-Starczewska, M., Grodzki, T., \& Kurpas, D. (2017). Relationships between quality of life in the psychological domain, acceptance of illness, and healthcare services in patients with asthma. In M. Pokorski (Ed.), Influenza and Respiratory Care. Advances in Experimental Medicine and Biology (Vol. 968, pp. 49-60). Springer.

Mroczek, B., Sitko, Z., Augustyniuk, K., Pierzak-Sominka, J., Wróblewska, I., \& Kurpas, D. (2015). Socioeconomic indicators shaping quality of life and illness acceptance in patients with chronic obstructive pulmonary disease. Advances in Experimental Medicine and Biology, 861, 19-30. https:// doi.org/10.1007/5584_2015_136

Nnoaham, K. E., Hummelshoj, L., Webster, P., D’Hooghe, T., de Cicco Nardone, F., de Cicco Nardone, C., Jenkinson, C., Kennedy, S. H., \& Zondervan, K. T. (2011). Impact of endometriosis on quality of life and work productivity: a multicenter study across ten countries. Fertility and Sterility, 96, 366-373.e8. https://doi.org/10.1016/j.fertnstert. 2011.05.090

Obiego, M., Siennicka, A., Jankowska, E. A., \& Danel, D. P. (2017). Direction of the relationship between acceptance of illness and health-related quality of life in chronic heart failure patients. Journal of Cardiovascular Nursing, 32, 348-356. https:// doi.org/10.1097/JCN.0000000000000365

Oxholm, D., Knudsen, U. B., Kryger-Baggesen, N., \& Ravn, P. (2007). Postmenopausal endometriosis. Acta Obstetricia et Gynecologica Scandinavica, 86, 1158-1164. https://doi.org/10.1080/000163407 01619407

Ozkan, S., Murk, W., \& Arici, A. (2008). Endometriosis and infertility: Epidemiology and evidence-based treatments. Annals of the New York Academy of Sciences, 1127, 92-100. https://doi.org/10.1196/annals. 1434.007
Qiu, C., Zhang, X., Zang, X., \& Zhao, Y. (2019). Acceptance of illness mediate the effects of health literacy on self-management behaviour. European Journal of Cardiovascular Nursing, 19, 411-420. https://doi. org/10.1177/1474515119885240

Quartana, P. J., Campbell, C. M., \& Edwards, R. R. (2009). Pain catastrophizing: a critical review. Expert Review of Neurotherapeutics, 9, 745-758. https://doi. org/10.1586/ern.09.34

Richardson, E. J., Ness, T. J., Doleys, D. M., Baños, J. H., Cianfrini, L., \& Scott Richards, J. (2009). Depressive symptoms and pain evaluations among persons with chronic pain: Catastrophizing, but not pain acceptance, shows significant effects. Pain, 147, 147-152. https://doi.org/10.1016/j.pain.2009.08.030

Rode, D., \& Rode, M. (2018). The relationship between self-esteem, sense of self-efficacy and level of illness acceptance, and healthful behaviours in patients with long-term illnesses (type II diabetes, Hashimoto's disease). Health Psychology Report, 6, 158-170. https://doi.org/10.5114/hpr.2018.71635

Rogon, I., Kasprzak, Z., \& Szcześniak, Ł. (2017). Perceived quality of life and acceptance of illness in people with type 2 diabetes mellitus. Przeglad Menopauzalny, 16, 79-85. https://doi.org/10.5114/pm. 2017.70583

Rosińczuk, J., \& Kołtuniuk, A. (2017). The influence of depression, level of functioning in everyday life, and illness acceptance on quality of life in patients with Parkinson's disease: a preliminary study. Neuropsychiatric Disease and Treatment, 13, 881-887. https://doi.org/10.2147/NDT.S132757

Rzońca, E., Iwanowicz-Palus, G., \& Bień, A. (2018). Generalized self-efficacy, dispositional optimism, and illness acceptance in women with polycystic ovary syndrome. International Journal of Environmental Research and Public Health, 15, 2484. https:// doi.org/10.3390/ijerph15112484

Selçuk, i., \& Bozdağ, G. (2013). Recurrence of endometriosis; risk factors, mechanisms and biomarkers; review of the literature. Journal of the Turkish German Gynecological Association, 14, 98-103. https:// doi.org/10.5152/jtgga.2013.52385

Sharpe, L., \& Curran, L. (2006). Understanding the process of adjustment to illness. Social Science and Medicine, 62, 1153-1166. https://doi.org/10.1016/ j.socscimed.2005.07.010

Somigliana, E., Ragni, G., Benedetti, F., Borroni, R., Vegetti, W., \& Crosignani, P. G. (2003). Does laparoscopic excision of endometriotic ovarian cysts significantly affect ovarian reserve? Insights from IVF cycles. Human Reproduction, 18, 2450-2453. https://doi.org/10.1093/humrep/deg432

Stratton, P., \& Berkley, K. J. (2010). Chronic pelvic pain and endometriosis: Translational evidence of the relationship and implications. Human Reproduction Update, 17, 327-346. https://doi.org/10.1093/ humupd/dmq050 
Sullivan, M. J. L., Thorn, B., Haythornthwaite, J. A., Keefe, F., Martin, M., Bradley, L. A., \& Lefebvre, J. C. (2001). Theoretical perspectives on the relation between catastrophizing and pain. The Clinical Journal of Pain, 17, 52-64. https://doi.org/10.1097/00002508200103000-00008

Trompetter, H. R., Bohlmeijer, E. T., Fox, J. P., \& Schreurs, K. M. G. (2015). Psychological flexibility and catastrophizing as associated change mechanisms during online Acceptance \& Commitment Therapy for chronic pain. Behaviour Research and Therapy, 74, 50-59. https://doi.org/10.1016/ j.brat.2015.09.001

Turner, J. A., Anderson, M. L., Balderson, B. H., Cook, A. J., Sherman, K. J., \& Cherkin, D. C. (2016). Mindfulness-based stress reduction and cognitive behavioral therapy for chronic low back pain: Similar effects on mindfulness, catastrophizing, self-efficacy, and acceptance in a randomized controlled trial. Pain, 157, 2434-2444. https://doi. org/10.1097/j.pain.0000000000000635

Uchmanowicz, I., Jankowska-Polańska, B., Motowidlo, U., Uchmanowicz, B., \& Chabowski, M. (2016). Assessment of illness acceptance by patients with COPD and the prevalence of depression and anxiety in COPD. International Journal of Chronic Obstructive Pulmonary Disease, 11, 963-970. https:// doi.org/10.2147/COPD.S102754

Valdes, A. M., Warner, S. C., Harvey, H. L., Fernandes, G. S., Doherty, S., Jenkins, W., Wheeler, M., \& Doherty, M. (2015). Use of prescription analgesic medication and pain catastrophizing after total joint replacement surgery. Seminars in Arthritis and Rheumatism, 45, 150-155. https://doi.org/10.1016/ j.semarthrit.2015.05.004

Vowles, K. E., McCracken, L. M., McLeod, C., \& Eccleston, C. (2008). The Chronic Pain Acceptance Questionnaire: Confirmatory factor analysis and identification of patient subgroups. Pain, 140, 284-291. https://doi.org/10.1016/j.pain.2008.08.012

Walsh, T., LeBlanc, L., \& McGrath, P. (2003). Menstrual pain intensity, coping, and disability: The role of pain catastrophizing. Pain Medicine, 4, 352-361. https://doi.org/10.1111/j.1526-4637.2003. 03039.x

Wright, D., Hoang, M., Sofine, A., Silva, J. P., \& Schwarzkopf, R. (2017). Pain catastrophizing as a predictor for postoperative pain and opiate consumption in total joint arthroplasty patients. Archives of Orthopaedic and Trauma Surgery, 137, 1623-1629. https:// doi.org/10.1007/s00402-017-2812-x

Zalewska, A., Miniszewska, J., Chodkiewicz, J., \& Narbutt, J. (2007). Acceptance of chronic illness in psoriasis vulgaris patients. Journal of the European Academy of Dermatology and Venereology, 21, 235242. https://doi.org/10.1111/j.1468-3083.2006.01912.x

Zarbo, C., Brugnera, A., Frigerio, L., Malandrino, C., Rabboni, M., Bondi, E., \& Compare, A. (2018). Be- havioral, cognitive, and emotional coping strategies of women with endometriosis: a critical narrative review. Archives of Women's Mental Health, 21, 1-13. https://doi.org/10.1007/s00737-017-0779-9
Predictors of illness acceptance in women with endometriosis 